\title{
Morning quiet-time ionospheric current reversal at mid to high latitudes
}

\author{
R. Stening ${ }^{1}$, T. Reztsova ${ }^{1}$, D. Ivers ${ }^{2}$, J. Turner ${ }^{2}$, and D. Winch ${ }^{2}$ \\ ${ }^{1}$ School of Physics, University of New South Wales, Sydney NSW 2052 Australia \\ ${ }^{2}$ School of Mathematics and Statistics, University of Sydney, Sydney 2006, Australia
}

Received: 21 July 2004 - Accepted: 31 October 2004 - Published: 28 February 2005

\begin{abstract}
The records of an array of magnetometers set up across the Australian mainland are examined. In addition to a well-defined current whorl corresponding to the ionospheric $S_{q}$ current system, another system of eastward flowing currents is often found in the early morning. The system is most easily identified at observatories poleward of the focus of the $S_{q}$ system, where a morning reversal from eastward to westward currents can be seen. The time of the reversal is usually later, sometimes up to $12 \mathrm{~h}$ local noon, in June (Southern Winter) than in other seasons. There is some evidence of a similar current system at other longitudes and in the Northern Hemisphere. An important outcome of the study is that it enables identification of which features of a daily variation of the northward magnetic field $\Delta X$ relate to an $S_{q}$ current whorl and which must be attributed to some other current system.
\end{abstract}

Key words. Ionosphere (Electric fields and currents; Midlatitude ionosphere) - Magnetospheric physics (Current systems)

\section{Introduction}

When we look at magnetic observatory records, we see variations of the magnetic field, including the Earth's main field, but it is often hard to identify the time of reversal of the ionospheric currents which are responsible for the daily variations. This problem has plagued researchers since early times. It was particularly difficult at low latitudes and at the magnetic equator because there is often just one peak in the daily variation of the horizontal component of the magnetic field, $\Delta H$, with time. We had to wait until another method of determination of the direction of current flow was developed. This arrived when Balsley (1969) measured electron drift velocities in the equatorial electrojet. He found that the current reversed direction within one hour of 06:30 LT. $F$-region vertical drift velocities reversed at the same time (Morriss and Lyon, 1966). Since the equatorial electrojet is

Correspondence to: R. Stening

(r.stening@unsw.edu.au) primarily driven by the electric field responsible for vertical $F$-region drifts, the reversal time of these drifts should also give a close approximation to the time of reversal of the electrojet current. Fejer et al. (1991) have since provided information on seasonal variations of the reversal time in the Peruvian electrojet. Knowledge of this reversal time placed an additional constraint on the modelling of the $S_{q}$ current system (Stening, 1970).

Recently, an examination was made of records from an array of more than fifty magnetic observatories spread across the Australian mainland. Details of this experiment may be found in Chamalaun and Barton (1993). The experiment is called AWAGS (Australia-Wide Array of Geomagnetic Stations). Often the $S_{q}$ current whorl was clearly seen in plots of the results from the magnetometer array, but observatories south of the focus, which would record a westward current as the whorl passed across them, showed an eastward current earlier in the day. This prompted an investigation into the daily variations of $\Delta H$ at observatories poleward of the $S_{q}$ focus. The times of reversal of the current at these latitudes will be another parameter which any modelling of the $S_{q}$ current will be required to fit.

\section{Examination of data}

For each observatory in the Australian mainland experiment, the one-minute data are averaged into an hourly mean. The hourly mean values have a linear trend removed and midnight values are subtracted to give a daily variation. The magnitude and direction of the horizontal component of the magnetic field are then determined and this vector is rotated clockwise through $90^{\circ}$ to represent an equivalent ionospheric current flow. Notice that the assumption that the ionospheric current flow is zero at midnight may not be exactly true on all occasions. Table 1 gives a list of the observatories referred to, their codes and their coordinates.

Figure 1 shows the changes in the overhead current system with time on 21 June 1990, when the $\Sigma K_{p}$ value for the day was $10^{+}$. A rough indication of the magnetic field deviation corresponding to the length of the arrows is given. 
Table 1. Coordinates of observatories used.

\begin{tabular}{|c|c|c|c|}
\hline \multicolumn{4}{|c|}{ Australian Observatories } \\
\hline Name & Code & $\begin{array}{l}\text { Geographic } \\
\text { latitude }\end{array}$ & $\begin{array}{l}\text { Geographic } \\
\text { latitude }\end{array}$ \\
\hline Cooktown & CKT & $15.5 \mathrm{~S}$ & $145.2 \mathrm{E}$ \\
\hline Derby & DER & $17.4 \mathrm{~S}$ & $123.7 \mathrm{E}$ \\
\hline Learmonth & LRM & $22.2 \mathrm{~S}$ & $114.1 \mathrm{E}$ \\
\hline Mt. Dare & MTD & $26.1 \mathrm{~S}$ & $135.2 \mathrm{E}$ \\
\hline Emu & EMU & $28.6 \mathrm{~S}$ & $132.2 \mathrm{E}$ \\
\hline Newcastle & NEW & $32.8 \mathrm{~S}$ & $151.8 \mathrm{E}$ \\
\hline Albany & $\mathrm{ABY}$ & $34.9 \mathrm{~S}$ & $117.8 \mathrm{E}$ \\
\hline Canberra & $\mathrm{CNB}$ & $35.3 \mathrm{~S}$ & $149.4 \mathrm{E}$ \\
\hline Toolangi & TOO & $37.5 \mathrm{~S}$ & $145.5 \mathrm{E}$ \\
\hline \multicolumn{4}{|l|}{ Other observatories } \\
\hline Name & Code & $\begin{array}{l}\text { Geographic } \\
\text { latitude }\end{array}$ & $\begin{array}{l}\text { Geographic } \\
\text { latitude }\end{array}$ \\
\hline Niemegk & NGK & $52.1 \mathrm{~N}$ & $12.7 \mathrm{E}$ \\
\hline Chambon la Forêt & CLF & $48.0 \mathrm{~N}$ & $2.3 \mathrm{E}$ \\
\hline Memambetsu & MMB & $43.9 \mathrm{~N}$ & $144.2 \mathrm{E}$ \\
\hline Tucson & TUC & $32.2 \mathrm{~N}$ & $249.2 \mathrm{E}$ \\
\hline Port Alfred & $\mathrm{CZT}$ & $46.4 \mathrm{~S}$ & $51.9 \mathrm{E}$ \\
\hline
\end{tabular}

We note a significant eastward current flow early in the morning before the $S_{q}$ whorl moves in from the east. The eastward current remains until 02:00 UT (10:00 LT) at ABY (Albany) in south-western Australia. On this day the focus of the $S_{q}$ current system appears to be near $30^{\circ} \mathrm{S}$ latitude at 02:00 UT but then moves up to north of $25^{\circ} \mathrm{S}$ at $4 \mathrm{~h}$. It is as if, at the earlier times, the eastern current system is strong enough to push the focus southward (giving a positive deviation to observatories around $25^{\circ} \mathrm{S}$ ), but later, at 04:00 UT, the $S_{q}$ current system is able to dominate. An examination of the magnetic field variations at four "corners" of the continent is instructive both in trying to find the true zero of the ionospheric current and in relating the observed variations to the overall current flow. In these diagrams (Fig. 2) zero is fixed as a running mean of midnight values over ten days and so the zero may be slightly different from that in the vector plots.

Looking at Albany in the southwest, the morning peak in the northward magnetic field, $X$, is evidence of the eastward current flow. The main westward flow does not start until after 10:00 LT. This and other features are related to the late arrival of the $S_{q}$ system on this day - the focus sits near 13:00-14:00 LT (see Fig. 1). At Toolangi (TOO) in the southeast the current turns from east to west even later, around 12:00 LT. The positive deviations at the northern stations, CKT and DER, last longer than in the south: in the early afternoon the $S_{q}$ current whorl contributes to the positive deviation in $X$ at the northern stations but to the negative deviation in the southern parts. In the west the negative deviation in $Y$ is larger than its later positive deviation. This is probably because, by the time the $S_{q}$ system reaches Albany, it is getting quite late in the afternoon (15:00-16:00 LT) and the ionospheric conductivity will have fallen. It is also worth noticing that some of the $\Delta Y$ variations have an "M shape", indicating a large northward current near noon and smaller southward currents in the morning and afternoon. This differs from the "classical" Southern Hemisphere $\Delta Y$ variation which has a morning to noon negative excursion and an afternoon positive excursion. The additional morning positive excursion, indicating southward currents, may possibly be related to the morning eastward currents. The morning maximum is especially clear at CKT where the minimum is almost missing. Again, the afternoon positive excursion is relatively weak because the ionospheric conductivity has fallen by the time it arrives. At lower latitudes such as CKT the extra early morning positive peak has sometimes been seen as part of an "invasion" of the Northern Hemisphere current system as described by Mayaud (1976). However, the authors suspect that this low-latitude effect will eventually be recognised as being caused by field-aligned currents.

Figure 1 shows that the morning eastward current system does not appear to be part of some current whorl, at least not of the same form as the usual $S_{q}$ whorl.

Overall in June-July 1990 an eastward current was usually observed during the local time period from 6 to around 11 h. On 2 June 1990, it can be seen in Fig. 3 that the current was still eastward at 12 noon, $135^{\circ} \mathrm{E}$ local time (see EMU and MTD which reverse to westward an hour later). $\Sigma K_{p}$ was $13-$. This example points out the considerable strength of the early morning current system as it holds up the arrival of the $S_{q}$ whorl until noon.

By contrast in December, March and April the early morning eastward current often does not extend beyond 08:00 LT. An example of this is shown in Fig. 4 for 3 December 1989, where the currents have started to turn westward at 08:00 LT. Later in this day the focus moves in at about $23^{\circ} \mathrm{S}$ latitude.

Figure 5 from 3 April 1990 is another good example showing the two current systems "meeting each other". In the east, where it is 09:00 LT, the $S_{q}$ current whorl can be seen approaching, while in the west, where the local time is $7 \mathrm{~h}$, the eastward current system is dominant. This picture is fairly typical of April, where the transition from eastward to westward currents occurs around 08:00 LT in central south Australia.

It is interesting to look at a series of ten days for the $X$ component in December 1989, as shown in Fig. 6. Three of the observatories CTA, NEW and TOO, are on the eastern side of Australia while the other two, LRM and ABY, are in the west. In several cases an "M" shape can be seen in the daily variation of $X$, particularly at Newcastle (NEW) and Toolangi (TOO). The morning maximum is part of the eastward current system under examination in this paper, the minimum is part of the $S_{q}$ current whorl and the afternoon maximum appears to be part of some other current system. The current vectors in Fig. 7 show that this is so. On some days Albany (ABY) has a clear positive deviation while Toolangi (TOO) is negative in the middle of the day (e.g. 8 

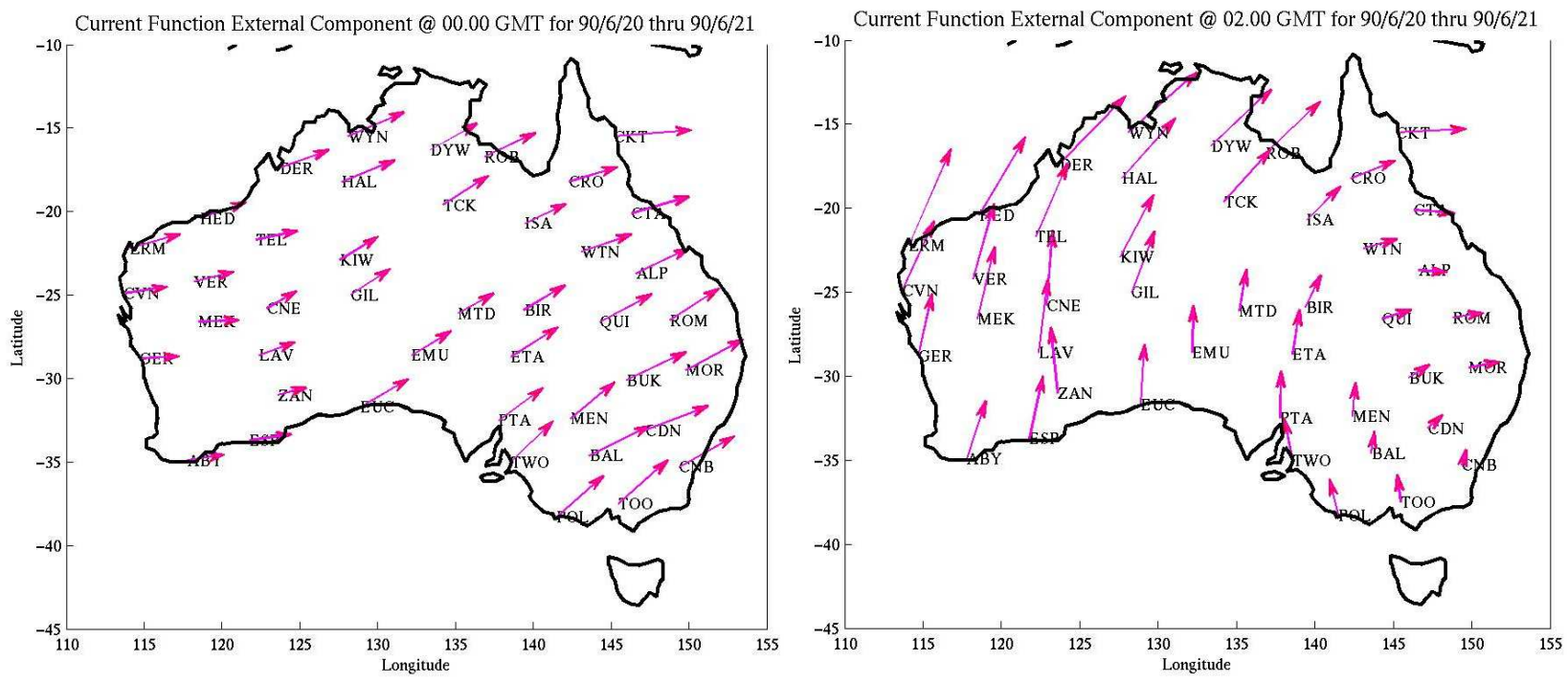

(With MidNight Subtracted)

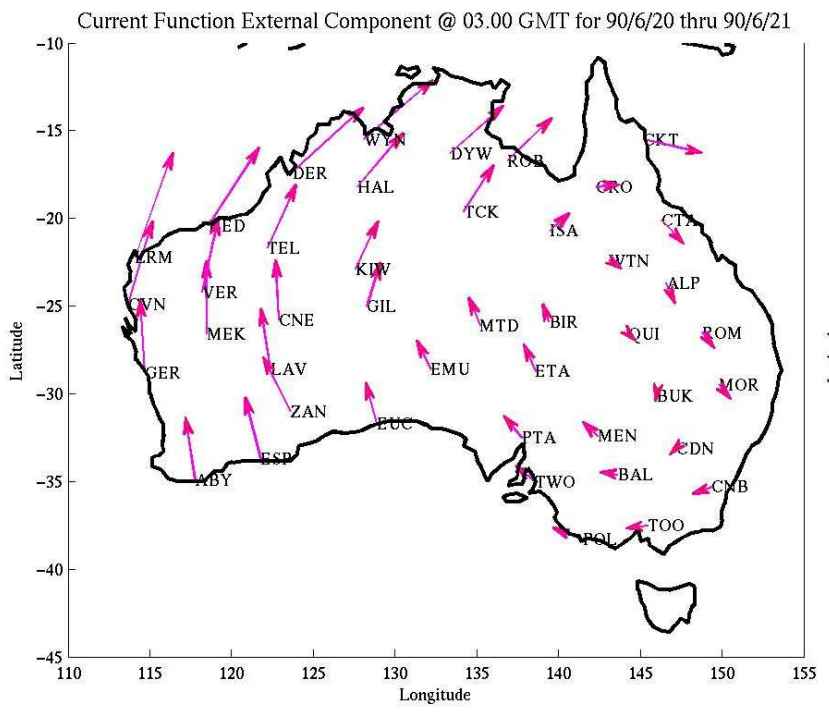

With MidNight Subtracted)

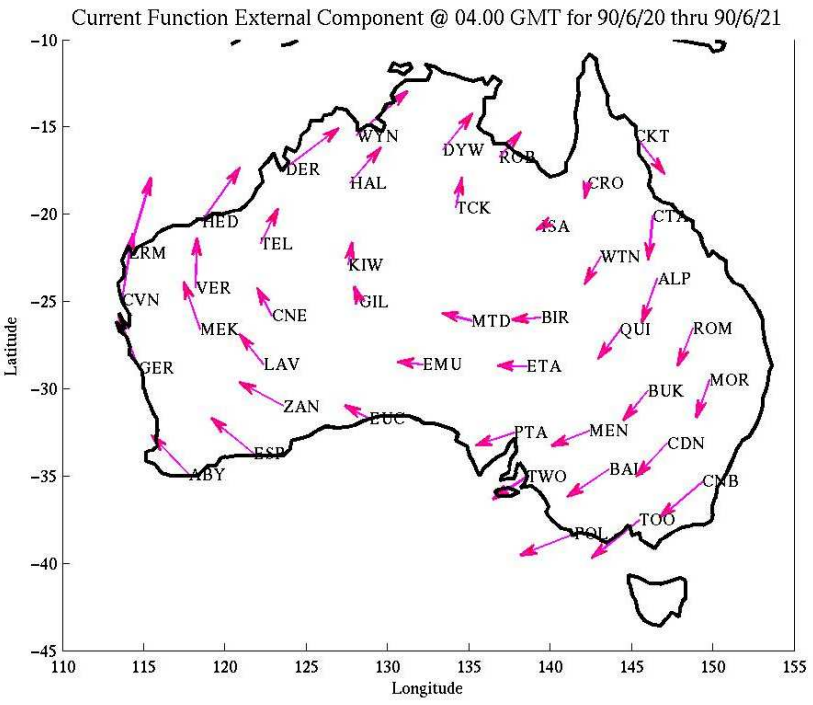

(With MidNight Subtracted)

(With MidNight Subtracted)

Fig. 1. Equivalent current systems over Australia on 21 June 1990 at 00:00, 02:00, 03:00 and 04:00 UT (09:00 to 13:00 LT at 135 longitude). An arrow length equivalent to $5^{\circ}$ of longitude westward corresponds to a magnetic field (rotated $90^{\circ}$ clockwise) of $27,25,21$ and $24 \mathrm{nT}$, respectively, 00:00, 02:00, 03:00 and 04:00 UT

and 9 December). On these days the focus is south of Albany but north of Toolangi. This indicates that the latitude of the $S_{q}$ focus has moved southward as it moves westward over the continent (see Stening, 1991). The next question is whether this phenomenon is unique to the Australian region.

Figure 8 shows a sample of $\Delta X$ (or $\Delta H$ ) variations from several observatories at different locations around the world for the same period in December 1989 as for Fig. 6. Four of these stations are in the Northern Hemisphere, where it is winter, and again we can see signs of early morning eastward currents, as evidenced by early morning positive deviations. Since a similar network to that provided by AWAGS is not available elsewhere, we cannot definitely confirm that a sim- ilar current system is in place at other longitudes, but the indications are that it might be so.

At Port Alfred in the Crozet Islands (CZT) in the southern Indian Ocean the $\mathrm{H}$ variation looks somewhat similar to that at Albany on 9 December. However, the morning maximum at CZT is at around 06:00-07:00 LT and the minimum is at 12:00-13:00 LT. The Albany maximum on 9 December is at 12:00 LT. So it appears that the correct interpretation is that the morning maximum at CZT is part of the morning eastward current system, which is under discussion here, while the noon minimum is related to the $S_{q}$ whorl whose focus is north of CZT. The amplitude of the morning maximum at CZT is around $40 \mathrm{nT}$. This is similar to the amplitudes at 

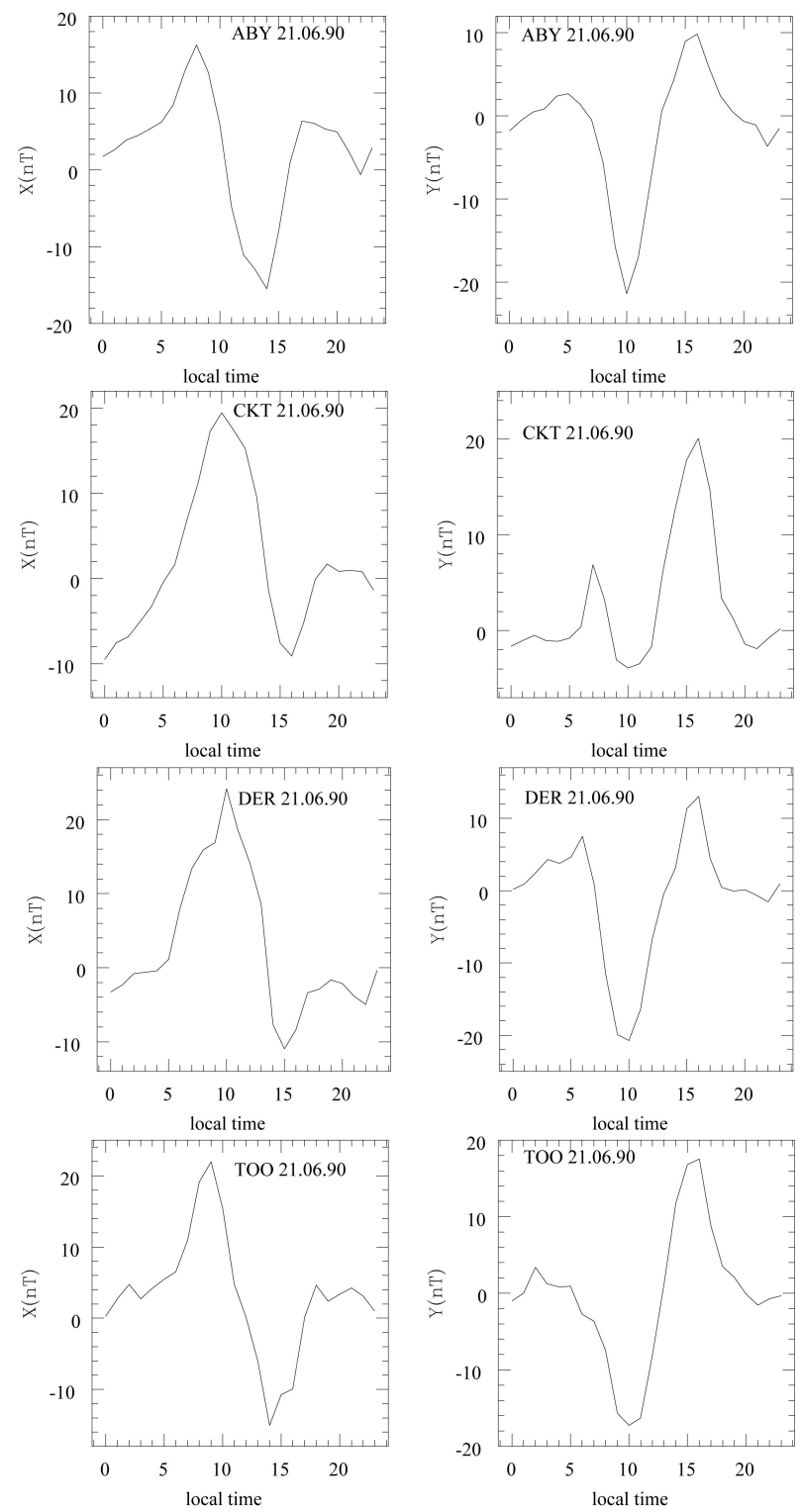

Fig. 2. Magnetic variations on 21 June 1990 at (a) Albany (ABY), (b) Cooktown (CKT), (c) Derby (DER) and (d) Toolangi (TOO). Hourly values of the northward $(X)$ and eastward $(Y)$ fields are plotted. The scales are in nanotesla.

the Australian observatories during this season. A similar variation is seen (but not shown here) at Port-aux-Francais (Kerguelen) (70.2 E, 49.3 S) which is at geomagnetic latitude $57.3 \mathrm{~S}$.

\section{Discussion}

It is hard to find traces of these morning eastward currents in earlier work. Takeda (1999) has performed spherical harmonic analyses of magnetic data and reconstructed equivalent currents. He finds predominantly north-south currents near dawn in the Southern Hemisphere in March and Decem-
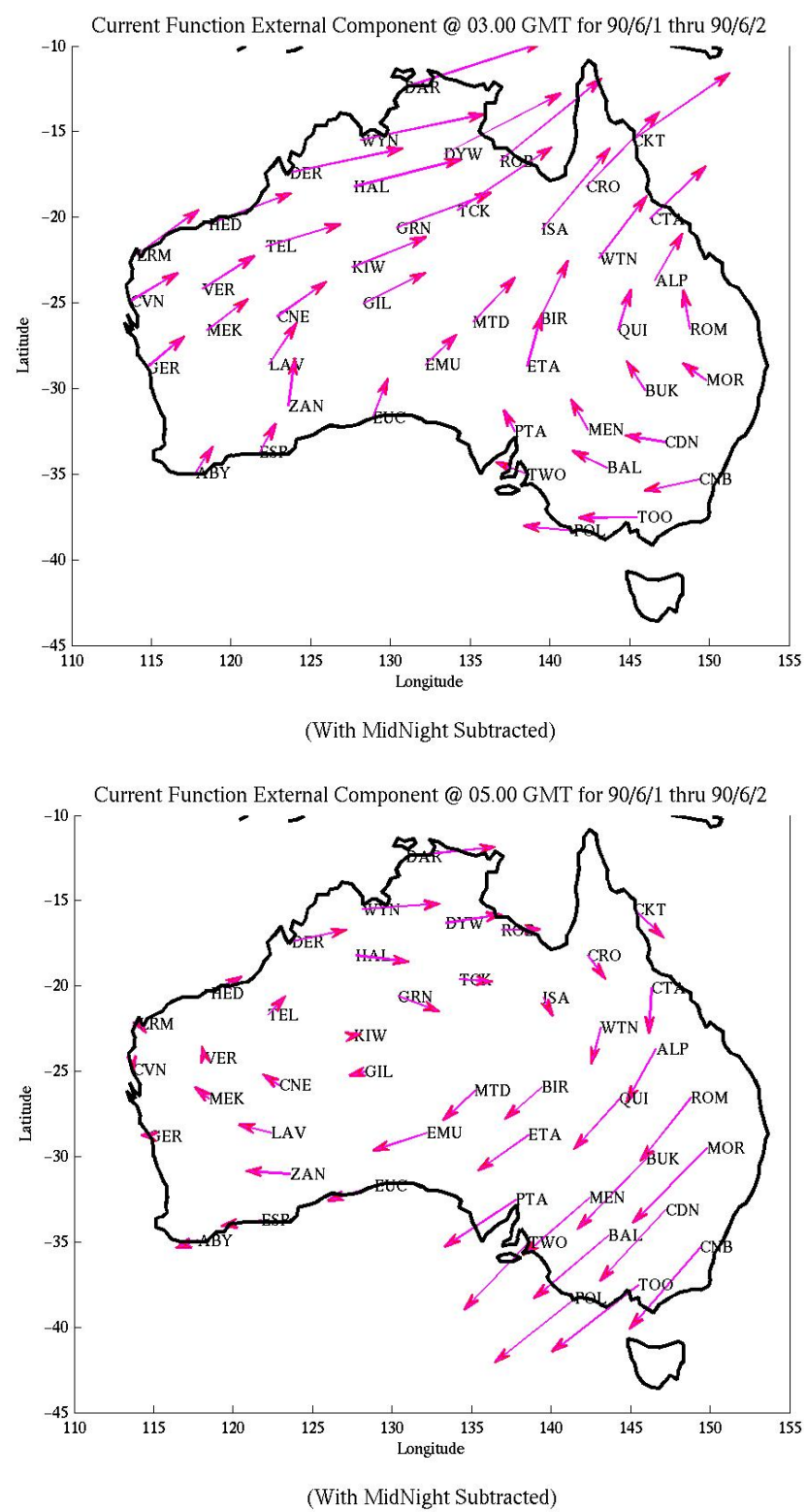

Fig. 3. As for Fig. 1 but at 03:00 and 05:00 UT on 2 June 1990. Arrow lengths: $5^{\circ}$ longitude length is equivalent to $22 \mathrm{nT}$ at 03:00 UT and to $25 \mathrm{nT}$ at 05:00 UT.

ber. In June his currents in Northern Australia appear as an "invasion" of the Northern Hemisphere current system, but there is little evidence of the morning eastward currents we are discussing. Some discussion of what happens to ionospheric current systems as they cross Australia was given by Stening and Hopgood (1991). The early morning peaks in $\Delta X$ are clearly visible in the data presented there but the limited data accessed by them at that time could not provide the insights which the AWAGS array has now given.

We should now ask what is the source of these early morning currents. Are they of magnetospheric or ionospheric origin? Are they a residual "disturbance effect" seen even on very quiet days or are they a component of the ionospheric dynamo driven by tidal winds in the ionosphere? 


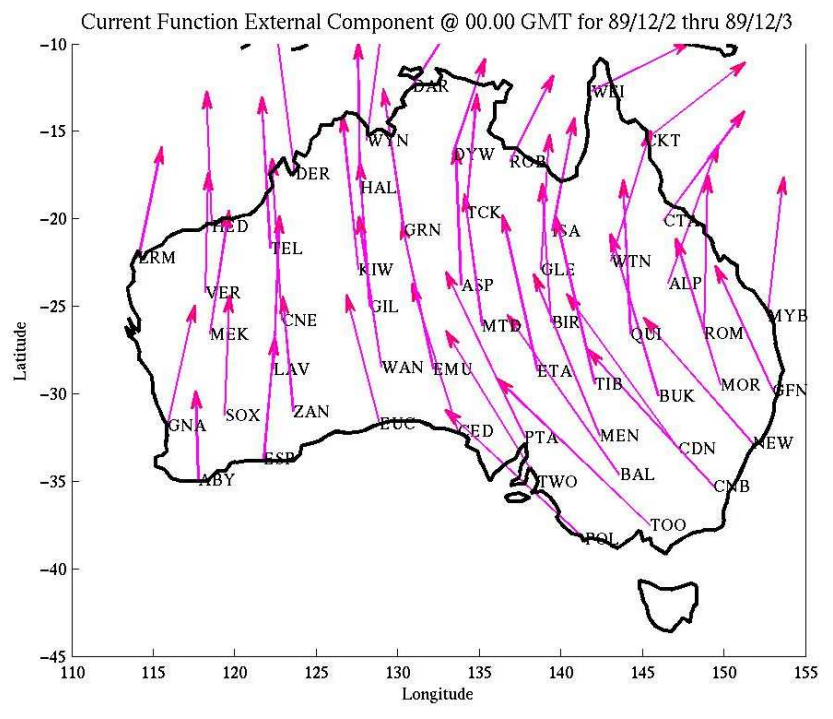

(With MidNight Subtracted)

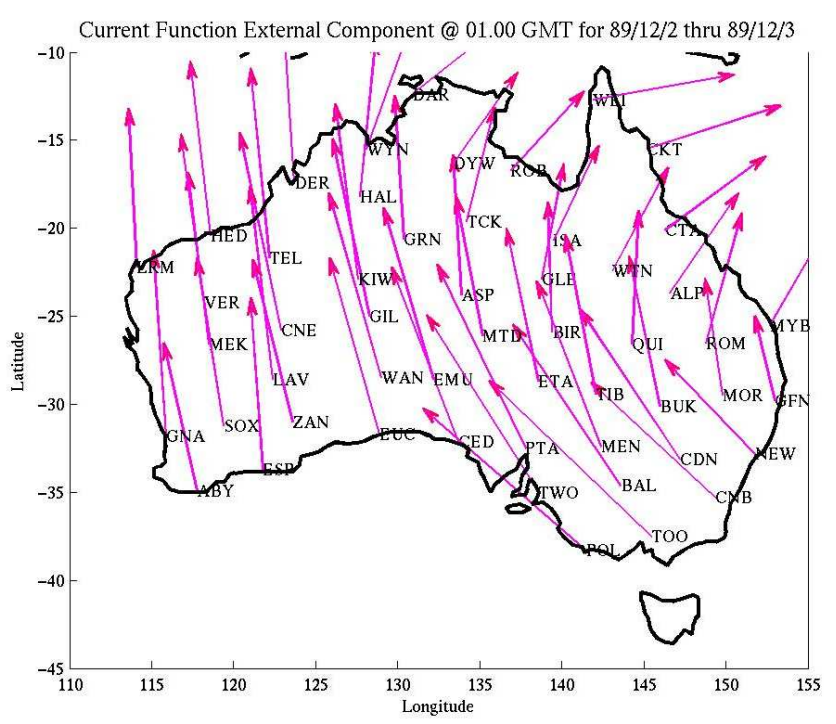

(With MidNight Subtracted)

Fig. 4. As for Fig. 1 but for 00:00 and 01:00 UT on 3 December 1989. Arrow lengths: $5^{\circ}$ longitude length is equivalent to $22 \mathrm{nT}$.

Mayaud (1976) examined data from Alibag and San Juan on very quiet days, seeking the signature of the quiet time magnetospheric currents predicted by Olson (1970a, b). He found that the predicted effect was practically indiscernible.

Another candidate might be the currents associated with $S_{q}{ }^{p}$, an "equivalent" electric current which flows in the polar cap region, but which, on occasion, may extend into lower latitudes. Iijima and Kokubun (1973) investigated $S_{q}{ }^{p}$ on a very quiet day and concluded that its effects did not extend to magnetic latitudes lower than $70^{\circ}$ on this occasion. In any case the expected current flow direction in the early morning is westward at lower latitudes and so cannot explain the present observations.

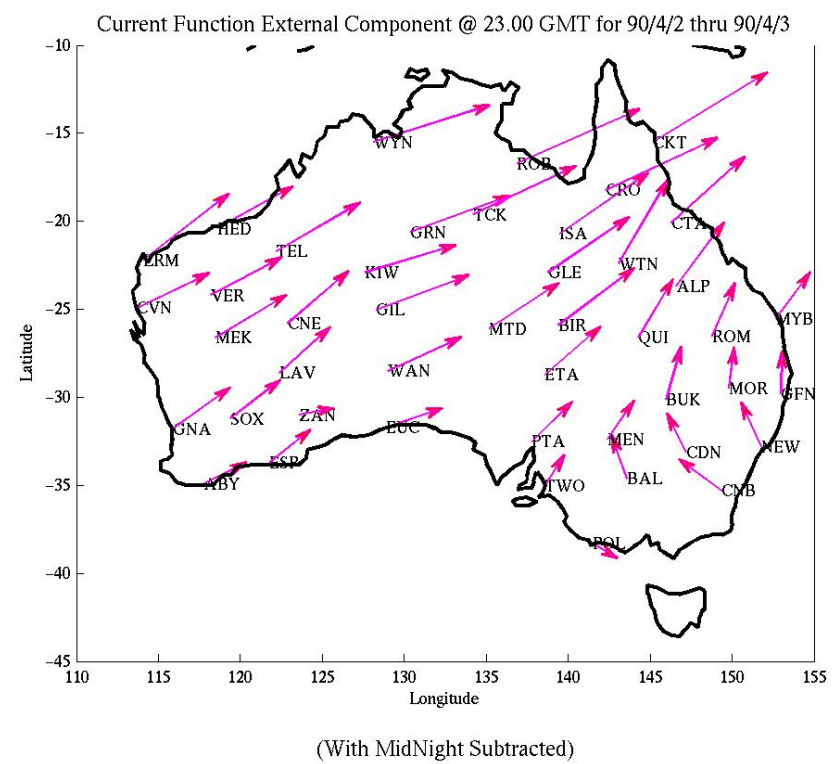

Fig. 5. As for Fig. 1 but for 23:00 UT on 2 April 1990. Arrow lengths: $5^{\circ}$ longitude length is equivalent to $30 \mathrm{nT}$.
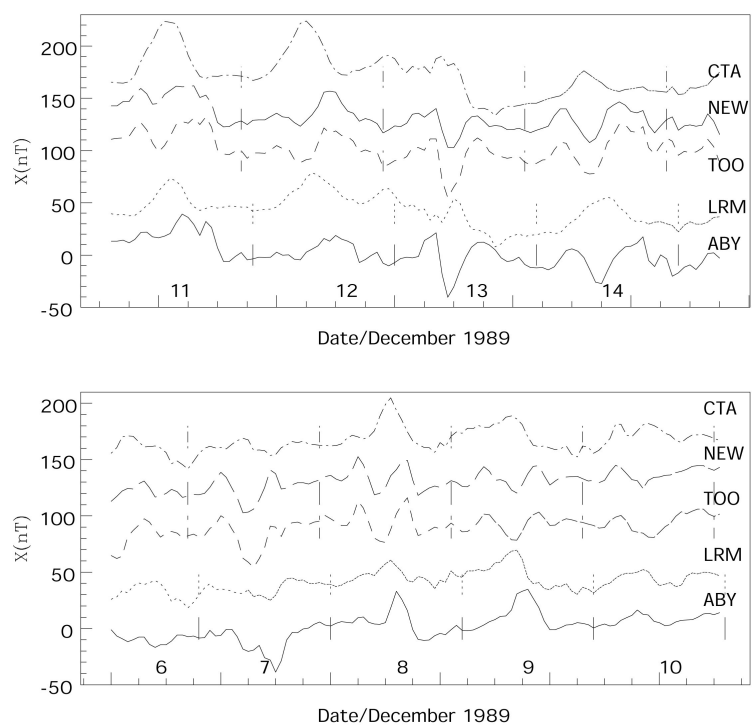

Fig. 6. A time series of the $X$ component hourly values from 6 to 14 December 1989. CTA (Charters Towers), NEW (Newcastle) and TOO (Toolangi) are in the east while LRM (Learmonth) and ABY (Albany) are in the west.

It should be noted that, when there is an " $\mathrm{M}$ " shape variation of $\Delta X$ near the focus, at least in the Australian region, the central (nearest midday) deviation is that corresponding to the $S_{q}$ whorl. The morning and afternoon deviations do not appear to derive from a whorl-like current distribution, at least not one with a focus in the $10^{\circ}-40^{\circ}$ latitude range over Australia. One might have imagined that secondary current whorls were present, as are sometimes seen in representations of the semidiurnal lunar tide (e.g. Matsushita, 1969) but this does not seem to be so. 


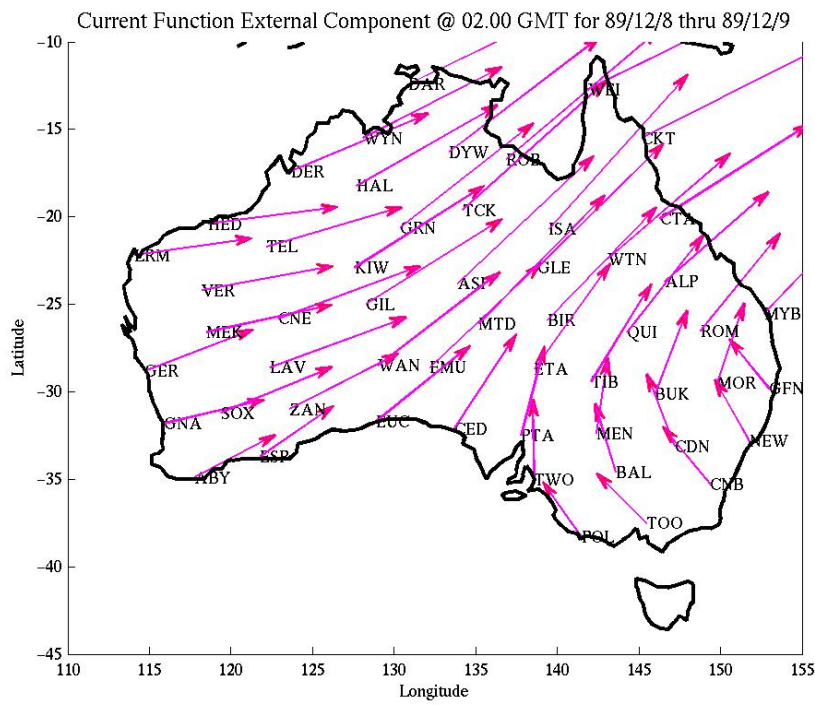

(With MidNight Subtracted)

Fig. 7. As for Fig. 1 but for 02:00 UT on 9 December 1989. Arrow lengths: $5^{\circ}$ longitude length is equivalent to $28 \mathrm{nT}$.

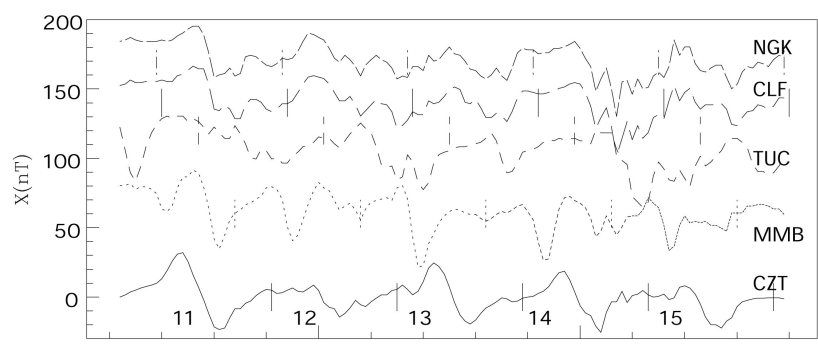

Date/December 1989

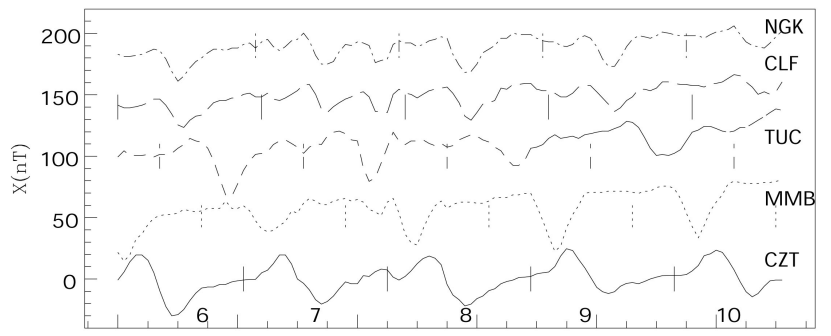

Date/December 1989

Fig. 8. A time series of $X$ component hourly values from 6 to 15 December 1989 from a range of observatories: NGK (Niemegk) in Eastern Germany, CLF (Chambon la Forêt) in France, TUC (Tucson) in Southern USA, MMB (Memambetsu) in Northern Japan and CZT (Port Alfred) in the Southern Indian Ocean.

We are left with the possibility that we are seeing the reversal of currents associated with the dynamo process and so any modelling of the $S_{q}$ system will need to reproduce this feature. However, the lack of any whorl-like structure to the early morning currents casts some doubt on this idea. Le Sager and Huang (2002) have suggested that field-aligned currents may make an important contribution near dawn but their model does not clearly demonstrate the effect presented here. Yamashita and Iyemori (2002) have presented evidence for field-aligned currents, using data from the Ørsted satellite. However, they show that the current direction reverses from summer to winter. This may explain effects in $\Delta Y$ but the morning eastward current emphasised here does not change direction with season.

\section{Conclusions}

1. With an array of magnetic observatories it is possible to identify which parts of the daily variation curve in $X$ or $H$ correspond to the $S_{q}$ current whorl.

2. An eastward flowing current system is often seen in the morning which has no whorl-like structure.

3. In Australia the reversal times from eastward to westward currents are generally later in June than in other seasons.

4. There are signs of similar morning currents at other longitudes and in the Northern Hemisphere.

5. The source of these morning eastward currents has not been definitely determined, but it does not appear to be part of the $S_{q}{ }^{p}$ system.

Acknowledgements. We are grateful to Francois Chamalaun and Charles Barton for making the AWAGS data set available to us. The overseas magnetic data were downloaded from the WDC1 site maintained by the Danish Meteorological Institute.

Topical Editor M. Lester thanks W.-Y. Xu for his help in evaluating this paper.

\section{References}

Balsley, B. B.: Measurement of electron drift velocities in the nighttime equatorial electrojet, J. Atmos. Terr. Phys., 31, 475-478, 1969.

Chamalaun, F. H. and Barton, C. E.: The large-scale electrical conductivity structure of Australia, J. Geomag. Geoelectr., 45, 12091212, 1993.

Fejer, B. G., de Paula, E. R., Gonzalez, S. A., and Woodman, R. F.: Average vertical and zonal $F$-region plasma drifts over Jicamarca, J. Geophys. Res., 96, 13 901-13 906, 1991.

Iijima, T. and Kokubun, S.: Geomagnetic $S_{q}{ }^{p}$ variation on an extremely quiet day, Rept. Ionos. Space Res. Japan, 27, 195-198, 1973.

Le Sager, P. and Huang, T. S.: Longitudinal dependence of the daily geomagnetic variation during quiet time, J. Geophys. Res., 107, A11, 1397 doi: 10.1029/2002JA009287, 2002.

Matsushita, S.: Dynamo currents, winds and electric fields, Radio Sci 4, 771-780, 1969.

Mayaud, P. N.: Magnetospheric and night-time induced effects in the regular daily variation $\mathrm{S}_{R}$, Planet Space Sci., 24, 1049-1057, 1976.

Morriss, R. W. and Lyon, A. J.: Equatorial ionospheric drifts, Nature, 210, 617-618, 1966. 
Olson, W. P.: Contribution of non-ionospheric currents to the quiet daily magnetic variations at the Earth's surface, J. Geophys. Res., 75, 7244-7249, 1970a.

Olson, W. P.: Variations in the Earth's surface magnetic field from the magnetopause current system, Planet Space Sci., 18, 14711484, 1970b.

Stening, R. J.: Tidal winds and the $S_{q}$ current system, Planet Space Sci. 18, 121-122, 1970.

Stening, R. J.: Variability of the equatorial electrojet: its relations to the $S_{q}$ current system and semidiurnal tides, Geophys. Res. Lett., 18, 1979-1982, 1991.
Stening, R. J. and Hopgood, P. A.: Geomagnetic quiet daily variations in the Australian region - Information from a new station at Charters Towers (20.1 ${ }^{\circ}$ S), J. Atmos. Terr. Phys. 53, 959-964, 1991.

Takeda, M.: Time variation of global geomagnetic $S_{q}$ field in 1964 and 1980, J. Atmos Solar Terr. Phys., 61, 765-774, 1999.

Yamashita, S. and Iyemori, T.: Seasonal and local-time dependences of the inter-hemispheric field-aligned currents deduced from the Ørsted satellite and the ground geomagnetic observations, J. Geophys. Res., 107, A11, 1372, doi: 10.1029/2002JA009414, 2002. 